\title{
Population aging in Korea: Changes since the 1960s
}

\author{
IK KI KIM ${ }^{1}$, JERSEY LIANG ${ }^{2}$, KA-OAK RHEE ${ }^{3}$ \& \\ CHEONG-SEOK KIM ${ }^{4}$ \\ ${ }^{1}$ Department of Sociology, Dongguk University, Seoul, Korea; ${ }^{2}$ Institute of Gerontology, The \\ University of Michigan, USA; ${ }^{3}$ Department of Social Welfare, Sungkonghoe University, \\ Korea; ${ }^{4}$ Population Studies Center, The University of Michigan, USA
}

\begin{abstract}
This study describes the characteristics of the Korean elderly. This study also investigates the population aging in conjunction with social and economic changes in Korea. Finally, this study explores social and economic implications with respect to the current and projected situation of the Korea elderly. Korean society has experienced very rapid changes both in demographic transition and population aging mainly due to the rapid processes of industrialization and urbanization, especially since 1960s. The rapid process of population aging has brought about the increase of dependency ratio, increasingly imbalanced sex ratio, and the decrease of the proportion of the elderly living with children. This paper concludes that the responsibility for the welfare of the elderly should shift from the family to the government.
\end{abstract}

Key words: Demographic transition, Population aging, Living arrangements, Functional disability, Filial piety, Korea

\section{Introduction}

Korean society has been undergoing great demographic changes as well as rapid socioeconomic development since the 1960s. Vast demographic changes have brought about the rapid increase in both the proportion and the absolute number of elderly in Korea. These processes of rapid population aging are likely to continue with the further improvement in living conditions and development of medical technology. Population aging raises various policy issues such as establishing income security, health care, and social welfare systems for the elderly in the future. Thus, it is necessary to investigate the current situation of the elderly as well as population aging trends in conjunction with economic changes in Korea.

The first goal of this paper is to describe characteristics of the current elderly population in Korea. Next, features of the population aging since the 1960 s will be examined along with its social and economic consequences. In particular, within the context of the demographic transition in Korea, the process of population aging will be examined in terms of the size and 
growth of the elderly population, causes of population aging, changes in the socioeconomic status, and living arrangements of the elderly population. Finally, social and economic implications of population aging in Korea will be explored with respect to the current and projected situation of the Korean elderly.

Population aging in Korea is distinguishable from the corresponding process in Western developed countries in mainly two aspects: the rapidity of population aging and the emphasis on family support for the elderly. Population aging is a natural outcome of the demographic transition from high fertility and mortality to low fertility and mortality. The rapidly changing socioeconomic and demographic characteristics, in conjunction with population aging in Korea, have created greater awareness and commitment among policy makers and planners to concerns regarding the elderly.

In formulating policy and programs, deliberate attention should be paid to the fact that Korean elderly in the future will be quite different from the present elderly in educational achievement, job experience, longevity, and health conditions. Further population heterogeneity, in terms of various subnational groupings within the country, should be taken into account in formulating programs for aging. The significant reliance on family support for the elderly also draws special attention of policy makers and planners.

As is widely known, countries in East Asia, including Japan, China, Taiwan, and Korea, have shared the ideals of filial piety (Hyo in Korean; Hsiao in Chinese; Ko in Japanese) for many generations (Sung 1990). Respect for the aged has strong roots in Korean culture. It is a value based on filial piety which has not yet been undermined by socioeconomic and demographic changes. In some ways, the filial piety tradition has been further highlighted by the changes within Korean society. Despite the forces of industrialization and urbanization, the family retains its role as the backbone of old age support (Choe 1989; Kim \& Choe 1992; Liang, Gu \& Krause 1992; Martin 1988; Sung 1990; Tu, Liang \& Li 1989). A better understanding of the process of population aging will facilitate the development of policies and plans to ensure meeting the needs of the Korean elderly at present as well as in the future and will also contribute knowledge regarding comparative experiences and strategies on aging issues among other Asian countries.

\section{Characteristics of the current Korean elderly population}

This section will address socioeconomic, demographic characteristics, and health status of the current Korean elderly population. The data for this section are primarily from the 1988 Korean National Health Survey, conducted by the Korea Institute for Health and Social Affairs. 
Table 1. Marital status of the elderly by age and sex, Korea, 1988

\begin{tabular}{|c|c|c|c|c|c|c|c|c|c|c|c|c|c|}
\hline \multirow[b]{2}{*}{$\begin{array}{l}\text { Marital } \\
\text { status }\end{array}$} & \multicolumn{3}{|c|}{ Total (age 60+) } & \multicolumn{2}{|l|}{$60-64$} & \multicolumn{2}{|l|}{$65-69$} & \multicolumn{2}{|l|}{$70-74$} & \multicolumn{2}{|l|}{$75-79$} & \multicolumn{2}{|l|}{$80+$} \\
\hline & & $\mathbf{M}$ & $\bar{F}$ & $\mathbf{M}$ & $\bar{F}$ & $\mathbf{M}$ & $\bar{F}$ & $\bar{M}$ & $\bar{F}$ & $\mathbf{M}$ & $\bar{F}$ & $\mathbf{M}$ & $\bar{F}$ \\
\hline Single & 0 & 0 & 0 & 0 & 0 & 0.1 & 0 & 0.1 & 0 & 0.1 & 0.1 & 0 & 0.1 \\
\hline Married & 52.4 & 85.8 & 30.4 & 92.7 & 47.2 & 88.4 & 32.9 & 82.1 & 23.2 & 73.4 & 14.4 & 56.2 & 4.0 \\
\hline Divorced & 0.7 & 0.6 & 0.7 & 0.7 & 1.2 & 0.8 & 0.7 & 0.4 & 0.4 & 0.5 & 0.3 & 0.3 & 0 \\
\hline Widowed & 45.8 & 12.4 & 67.8 & 5.9 & 50.1 & 9.4 & 65.1 & 15.5 & 75.5 & 25.0 & 84.3 & 41.7 & 95.7 \\
\hline Separated & 1.1 & 1.2 & 1.1 & 0.7 & 1.5 & 1.3 & 1.3 & 0.9 & 0.9 & 1.0 & 0.8 & 1.9 & 0.2 \\
\hline Total (\%) & 100.0 & 100.0 & 100.0 & 100.0 & 100.0 & 100.0 & 100.0 & 100.0 & 100.0 & 100.0 & 100.0 & 100.0 & 100.0 \\
\hline Number & & & & & & & & & & & & & \\
\hline $\begin{array}{l}\text { of } \\
\text { elderly }\end{array}$ & 19560 & 7775 & 11785 & 2996 & 3827 & 2212 & 2993 & 1382 & 2258 & 765 & 1496 & 420 & 1211 \\
\hline
\end{tabular}

Adapted from Rhee, Kwon, Ahn \& Jung (1989: 67).

Sounce: KIHASA, National Health Survey Korea (1988).

\section{Marital status}

Population distribution in terms of marital status of the elderly is indicated in Table 1. The proportions of single, divorced, and separated elderly are extremely low, together comprising less than $2 \%$ for each sex. The majority of Korean elderly are either widowed or currently married, but there are large gender differences. Among males aged 60 and over, the proportion currently married is $85.8 \%$, and the proportion widowed is only $12.4 \%$. For females aged 60 and over, the corresponding proportions are 30.4 and $67.8 \%$, respectively. As age increases, the proportion of the elderly population currently married decreases and the proportion widowed increases for both sexes. But the gender difference in the proportion married is still distinctive in the oldest age group, 80 years of age and over, with $56.2 \%$ of the males being married versus $4 \%$ for their female counterparts.

\section{Economic activity}

The 1988 survey indicates that the labor force participation rate among those aged 60 and over is $34.7 \%$. Among males aged 60 and over, almost half of them are currently active in the labor force. However, the labor force participation rate of females aged 60 and over is smaller, i.e., $24.9 \%$. One reason for this relatively high proportion of the elderly in the labor force is that the majority of old workers, approximately $75 \%$, are engaged in farming and fishing. For both sexes, however, the labor force participation rates decreases as age advances. However, the labor force participation rates among those 
Table 2. Educational attainment of the elderly by age and sex, Korea, 1988

\begin{tabular}{|c|c|c|c|c|c|c|c|c|c|c|c|c|c|}
\hline \multirow{2}{*}{$\begin{array}{l}\text { Educational } \\
\text { attainment }\end{array}$} & \multicolumn{3}{|c|}{ Total (age $60+$ ) } & \multicolumn{2}{|l|}{$60-64$} & \multicolumn{2}{|l|}{$65-69$} & \multicolumn{2}{|l|}{$70-74$} & \multicolumn{2}{|l|}{$75-79$} & \multicolumn{2}{|l|}{$80+$} \\
\hline & & $\overline{\mathrm{M}}$ & $\overline{\mathrm{F}}$ & $\mathbf{M}$ & $\overline{\mathrm{F}}$ & $\mathbf{M}$ & $\bar{F}$ & $\bar{M}$ & $\bar{F}$ & $\bar{M}$ & $\mathbf{F}$ & $\mathbf{M}$ & $\bar{F}$ \\
\hline No school & 60.0 & 39.4 & 73.7 & 23.0 & 57.8 & 39.3 & 72.2 & 51.5 & 82.0 & 61.9 & 88.5 & 76.0 & 93.6 \\
\hline Elementary & & & & & & & & & & & & & \\
\hline $\begin{array}{l}\text { school } \\
\text { Middle }\end{array}$ & 27.3 & 35.8 & 21.6 & 41.9 & 33.8 & 37.7 & 23.1 & 31.5 & 15.7 & 25.8 & 9.6 & 15.1 & 5.1 \\
\hline school & 5.9 & 11.3 & 2.3 & 15.9 & 4.4 & 10.7 & 2.2 & 8.3 & 0.8 & 5.6 & 0.8 & 3.0 & 0.4 \\
\hline $\begin{array}{l}\text { High } \\
\text { school }\end{array}$ & 4.1 & 7.3 & 2.0 & 10.5 & 3.3 & 6.8 & 2.1 & 4.8 & 1.2 & 3.3 & 9.8 & 3.0 & 0.5 \\
\hline College & & & & & & & & & & & & & \\
\hline and above & 2.7 & 6.1 & 0.4 & 8.8 & 0.6 & 5.5 & 0.4 & 3.9 & 0.3 & 3.4 & 0.2 & 2.9 & 0.4 \\
\hline Total (\%) & 100.0 & 100.0 & 100.0 & 100.0 & 100.0 & 100.0 & 100.0 & 100.0 & 100.0 & 100.0 & 100.0 & 100.0 & 100.0 \\
\hline $\begin{array}{l}\text { Number of } \\
\text { elderly }\end{array}$ & 19478 & 7737 & 11741 & 2980 & 3808 & 2210 & 2995 & 1374 & 2249 & 764 & 1410 & 418 & 1208 \\
\hline
\end{tabular}

Adapted from Rhee, Kwon, Ahn \& Jung (1989: 69).

Source: KIHASA, National Health Survey Korea (1988).

aged 60 to 64 years are $63.2 \%$ for males and $39.9 \%$ for females while for those aged 80 and over, the rates are $14.3 \%$ for males and $3.4 \%$ for females.

\section{Educational attainment}

The educational attainment of elderly by sex and age is presented in Table 2 . The data show that the majority of the elderly did not go to school. However, there are also big gender differences in educational attainment. The educational breakdown of the elderly population aged 60 are: $60 \%$ no school; $27.3 \%$ elementary school graduate; $5.9 \%$ middle school graduate; $4.1 \%$ high school graduate; and $2.7 \%$ college graduate and above. The proportion of elderly males reporting 'no school' is only $39.4 \%$ while the proportion for females is $73.7 \%$. Similarly, the proportion of high school graduates or over for the male elderly is $13.4 \%$ with only $2.4 \%$ of the female elderly with the same level of education. This sex difference is more distinctive in the oldest age groups. Moreover, with increasing age, educational attainment for both sexes consistently decreases.

\section{Self-report of chronic disease}

Among the surveyed elderly, $33.5 \%$ reported having one or more chronic disease. Interestingly, the proportion reporting chronic disease slightly increases up to the age group of 70-74, but then sharply decreases. The proportion reporting chronic disease seems to be significantly different between males 
Table 3. Chronic disease patterns of the elderly by age, Korea, 1988

\begin{tabular}{|c|c|c|c|c|c|c|}
\hline $\begin{array}{l}\text { Classification } \\
\text { chronic disease }\end{array}$ & $\begin{array}{l}\text { Total (age 60+) } \\
\text { Total }\end{array}$ & $\begin{array}{l}60-64 \\
\text { Total }\end{array}$ & $\begin{array}{l}65-69 \\
\text { Total }\end{array}$ & $\begin{array}{l}70-74 \\
\text { Total }\end{array}$ & $\begin{array}{l}75-79 \\
\text { Total }\end{array}$ & $\begin{array}{l}80+ \\
\text { Total }\end{array}$ \\
\hline $\begin{array}{l}\text { Endocrine and } \\
\text { metabolic illness and } \\
\text { immune deficiency }\end{array}$ & 4.4 & 6.2 & 4.6 & 3.8 & 2.1 & 0.5 \\
\hline $\begin{array}{l}\text { Neural and sensory } \\
\text { disorder }\end{array}$ & 27.8 & 24.7 & 29.8 & 28.8 & 29.9 & 29.7 \\
\hline Circulatory disease & 18.5 & 18.3 & 19.3 & 19.1 & 18.5 & 13.3 \\
\hline Respiratory illness & 6.5 & 5.9 & 6.0 & 8.3 & 6.0 & 6.9 \\
\hline $\begin{array}{l}\text { Gastrointestinal } \\
\text { disorder }\end{array}$ & 10.6 & 13.8 & 9.5 & 9.8 & 7.0 & 6.9 \\
\hline $\begin{array}{l}\text { Muscular-skeletal } \\
\text { disorder } \\
\text { Syndrome and }\end{array}$ & 16.0 & 17.1 & 15.8 & 15.7 & 16.8 & 10.4 \\
\hline ill-defined disorder & 10.6 & 8.0 & 9.5 & 9.5 & 14.6 & 26.7 \\
\hline Others & 5.6 & 6.0 & 5.1 & 5.1 & 5.1 & 5.7 \\
\hline Total (\%) & 100.0 & 100.0 & 100.0 & 100.0 & 100.0 & 100.0 \\
\hline Number of elderly & 6535 & 2208 & 1826 & 1347 & 738 & 416 \\
\hline
\end{tabular}

Adapted from Rhee, Kwon, Ahn \& Jung (1989: 84).

Source: KIHASA, National Health Survey Korea (1988).

and females for certain age groups. However, the proportion reporting chronic disease for female elderly is higher than for male elderly from age 60 to 70 . After age 70, the proportion reporting chronic disease for females is lower than for males.

As indicated in Table 3, 'neural and sensory disorder' (including dementia) is the most prevalent chronic disease among the total Korean elderly population $(27.8 \%)$, followed by 'circulatory disease' (18.5\%), 'gastrointestinal disorder' (10.6\%), and 'syndrome and ill defined disorder, trauma and intoxication' which includes conditions such as senile infirmity, numbness, and headache. However, the proportions of prevalent chronic disease differ by the age groups. For those aged 60 to 64 years, 'neural and sensory disorder' is the highest at $24.7 \%$, then 'circulatory disease' at $18.3 \%$, and then 'gastrointestinal disorder' at $13.8 \%$. Among those aged 70 to 74 years, 'neural and sensory disorder' is also first at $28.8 \%$, but is followed by 'gastrointestinal disorder' at $9.8 \%$. For the oldest Koreans, aged 80 and over, the most prevalent disorder is 'neural and sensory' at $29.7 \%$, followed by 'syndrome and ill defined disorder, trauma and intoxication' at $26.7 \%$, then 'circulatory disease' at $13.3 \%$, and finally 'gastrointestinal disorder' at $6.9 \%$. 


\section{Self-report of functional disability}

According to a survey on self-assessment of health status in Korea (Rhee, Kwon \& Kang 1991), 52\% of the elderly report 'generally healthy'. Fortyone per cent of the elderly answer 'often sick', 6.3\% reply 'frequently ill in bed' and the other $0.8 \%$ say 'cannot move at all'.

The proportion of those who reply 'generally healthy' decreases with increasingly older cohorts, whereas the proportion of those who answer 'often sick' is increasing with older age. The proportion of those who answer either 'frequently ill in bed' or 'cannot move at all' is as follows: $6.3 \%$ among those aged 60 to 64 years, 3.2\% among those aged 65 to 69 years, $6.8 \%$ among those aged 70 to 74 years, $12.7 \%$ among those aged 75 to 79 years and $17.9 \%$ among those aged 80 and over.

The elderly who are physically ill need someone to help them in the activities of daily living (ADL). One out of five elderly needs help in preparation for food and cooking. The proportion of those who always need help in these activities is $8.3 \%$ and the proportion of those who often need help is $11.9 \%$. The proportion of the elderly who always need help in cleaning houses or doing laundry is $10.5 \%$ and the proportion of those who often need help is $13.7 \%$. The proportion of the elderly who need help in taking a bath is about $9 \%$. The proportion of those who need help in cleaning clothes is $4.1 \%$. The proportion of those who need help in using the toilet is $3.4 \%$.

\section{Causes of death}

Between 1983 and 1992, the most prevalent cause of death among those aged 60 years and over was 'cardio-pulmonary disease and other heart disease'. During this same period, the corresponding cause of death for those aged 70 and over was 'cerebrovascular disease or cerebrovascular accident'. Regarding changes in the relative proportion of various death-causes during this period, the increase of 'malignant neoplasm' was most striking. The proportion of 'malignant neoplasm' as the cause of death for those aged 60 and over rose from $10.6 \%$ in 1983 to $20.1 \%$ for those aged 70 and over.

\section{Features of population aging in Korea since 1960}

Korea has witnessed a series of population change since the beginning of the 20 th century. The first sign of change was reflected in the mortality rate. Korea entered the first stage of mortality transition in the 1910s (Lee 1980). The crude death rate started to drop from around 34 per thousand in the 1910s. Since that time, the mortality rate showed a consistent pattern of decline until 
the period of the Korean War, 1950-1953. On the other hand, the fertility rate did not show any significant pattern of change up to this time (crude birth rate was around 40 per thousand). The gap between the fertility and mortality rates had increased over time, resulting in an unprecedented rapid population growth.

The decade of 1945-1955 in Korea reflected a period of disturbance in the demographic situation along with political, social, and economic turmoil (Kwon, Lee, Chang \& Yu 1975). The liberation of Korea in 1945 from Japanese colonization had resulted in the division of Korea into North and South. This liberation and partition of the country brought about a vast redistribution of the Korean population all over the country.

Population trends after the Korean War differ in many respects from those of previous periods. Korea entered the second stage of the mortality transition through the introduction of new medical procedures and health systems, particularly the introduction of antibiotics. In the mean time, Korea experienced a new era of 'baby boom', which reached a peak in 1959.

Following 1955-1960, the Korean population grew at the rate of approximately $3 \%$ annually. After the beginning of the 1960 s, South Korea experienced a major population transition, from a rapidly growing population to a moderately growing one. The annual growth rate of population has continuously declined over time. The record high growth rate of $3 \%$ in 1960 declined to $2.2 \%$ in 1970 , then to $1.7 \%$ in 1975 .

The rapid process of demographic transition in Korea was facilitated by the interaction of rapid socioeconomic development and full-scale adoption of family planning programs since the 1960s (Kim 1987). During the period of the first five-year economic plan, 1962-1967, the Gross National Product (GNP) grew at an annual rate of 7.0\%. The GNP growth for the next five-year economic plan was even higher, $11.4 \%$. Since then, the Korean economy has consistently grown over time.

It was 1962 that the national family planning programs were first implemented. The homogeneity of Korean people both in race and language has been conducive to the success of the program. A good communication network and administrative power have also helped. Also, the national desire for economic development has brought the population problem to the forefront at a critical time. The overall performance of the Korean national family planning programs was unsurpassed in the 1960s and thereafter in comparison with those of other developing countries (Kim, Ross \& Worth 1972).

\section{Demographic transition and population aging}

The rapid process of demographic transition has brought about an increase in both the absolute number and proportion of the elderly in Korea. Those aged 
Table 4. Proportions of the elderly, 1966-2020

\begin{tabular}{lrrrrrr}
\hline Age & 1966 & 1970 & 1975 & 1980 & 1985 & 1990 \\
\hline $0-14$ & 43.5 & 42.1 & 38.1 & 33.8 & 30.0 & 25.7 \\
$15-59$ & 51.3 & 52.5 & 56.3 & 60.1 & 63.1 & 66.6 \\
$60+$ & 5.2 & 5.4 & 5.6 & 6.1 & 6.9 & 7.7 \\
Total & 100.0 & 100.0 & 100.0 & 100.0 & 100.0 & 100.0 \\
\hline & & & & & & \\
Age & 1995 & 2000 & 2005 & 2010 & 2015 & 2020 \\
\hline $0-14$ & 23.7 & 21.2 & 20.3 & 19.1 & 17.4 & 16.1 \\
$15-59$ & 67.3 & 68.1 & 67.5 & 67.2 & 67.6 & 64.4 \\
$60+$ & 9.0 & 10.7 & 12.2 & 13.7 & 15.0 & 19.5 \\
Total & 100.0 & 100.0 & 100.0 & 100.0 & 100.0 & 100.0 \\
\hline
\end{tabular}

Sources: Economic Planning Board, Population and Housing Census Report (1966, 1970, 1975, 1980, 1985, 1990); Statistics Bureau, Future Projected Population 1990-2021 (1990).

60 and over increased from 1.5 million in 1960 to 3.3 million in 1990, and are projected to increase to 9.9 million by the year 2020. In total numbers, the elderly population aged 60 and over has doubled within the past three decades and is expected to increase by almost three times that of the 1990 figure and more than six times that of the 1960 figure. The proportion of those aged 60 and over was $5.2 \%$ in 1966 , and then consistently increasing up to $7.7 \%$ in 1990. The proportion of those aged 60 and over is projected to increase to $19.5 \%$ by the year 2020 (see Table 4 ).

The decreased proportion of those aged 60 and over between 1960 and 1966 is the result of the predominate rate of increase in the young population over any other component of the population. It is speculated that the increased proportion of the young population is due to the baby boom cohorts after Korean War (1950-1953) and sustained high fertility before the effective implementation of family planning program by the Korean government at the beginning of 1960s.

\section{Causes of population aging}

It has been demonstrated that population aging is essentially due to declines in fertility and that mortality decline in general has little effect on the age structure (Coale 1964). The effect of mortality decline on population aging, even though the magnitude of its effect is negligible compared to that of fertility decline, depends on the mortality level. While typical improvements in health and medicine produce the greatest increases in survivorship among the 
Table 5. Mortality and fertility in Korea, 1960-2025

\begin{tabular}{|c|c|c|c|c|c|c|c|c|}
\hline \multirow{2}{*}{ Indicators } & & \multicolumn{5}{|l|}{ Estimates } & & \\
\hline & & $1960-65$ & $1965-70$ & $1970-75$ & $1975-80$ & $1980-85$ & & \\
\hline CBR $(/ 1000)$ & & 39.9 & 36.3 & 31.0 & 23.6 & 21.5 & & \\
\hline $\operatorname{CDR}(/ 1000)$ & & 12.5 & 10.6 & 8.7 & 6.4 & 6.0 & & \\
\hline TFR(Noman) & & 5.5 & 5.3 & 4.6 & 3.0 & 2.5 & & \\
\hline \multicolumn{9}{|c|}{ Life expectancy at birth } \\
\hline Males & & 53.6 & 56.0 & 59.2 & 62.3 & 64.5 & & \\
\hline Females & & 56.9 & 59.5 & 64.1 & 68.8 & 71.0 & & \\
\hline \multirow[t]{2}{*}{ Both sexes } & & 55.4 & 57.8 & 61.7 & 65.6 & 67.8 & & \\
\hline & \multicolumn{8}{|c|}{ Medium variant projection } \\
\hline Indicators & $1985-90$ & $1990-95$ & $1995-00$ & $2000-05$ & $2005-10$ & $2010-15$ & $2015-20$ & $2020-25$ \\
\hline $\operatorname{CBR}(/ 1000)$ & 18.8 & 18.6 & 17.5 & 15.6 & 13.8 & 13.0 & 12.6 & 12.2 \\
\hline $\operatorname{CDR}(/ 1000)$ & 5.9 & 5.9 & 6.0 & 6.2 & 6.6 & 7.1 & 7.8 & 8.4 \\
\hline TFR(/Woman) & 2.0 & 1.9 & 1.9 & 1.9 & 1.9 & 1.9 & 1.8 & 1.8 \\
\hline \multicolumn{9}{|c|}{ Life expectancy at birth } \\
\hline Males & 66.1 & 67.6 & 68.7 & 69.9 & 70.8 & 71.6 & 72.5 & 73.3 \\
\hline Females & 72.6 & 73.8 & 75.0 & 76.0 & 77.0 & 77.9 & 78.7 & 79.4 \\
\hline Both sexes & 69.4 & 70.8 & 70.2 & 73.0 & 73.9 & 74.7 & 75.5 & 76.3 \\
\hline
\end{tabular}

Source: United Nations, World Population Prospects 1990 (1991: 452-453).

young rather than the old, declining mortality makes the population younger. This effect of declining mortality is offset and obscured by the much more powerful influence of falling fertility rates on population aging. However, when the life expectancy at birth increases to 70 years or more and thereby any gains in longevity concentrates at older ages, improved mortality makes the population older (Myers 1983).

The projections of mortality and fertility rates with medium variant by 2025 , as well as their trends between 1960 s and early 1980 s are presented in Table 5. During the period of 1960-1965, the crude birth rate (CBR) and total fertility rate (TFR) were 39.9 per thousand and 5.5 per woman, respectively. These fertility rates continued to decline during the following two decades. After 20 years, both the CBR and TFR dropped almost by one half, with the corresponding rates during $1980-1985$ at 21.5 and 2.5 . Fertility rates are projected to drop continuously until the period of 2020-2025.

Along with the rapid decline in fertility since the 1960 s, the observed and projected mortality rates also show dramatic improvement. The crude death rate (CDR) of 12.5 per thousand during the period of 1960-1965 dropped to 6 per thousand after 20 years (1980-1985). The declining CDR is projected to continue until the turn of this century. At that time, the CDR is expected to increase again and to reach 8.4 per thousand by $2020-2025$. The pattern 
of the CDR change between the 1960s and the 2020s, first decreasing and then increasing, is an outcome of population aging. This is because CDR as a crude measure of mortality is influenced by the age structure: CDR is high in older populations and low in younger populations.

Life expectancy has shown great increases since the 1960s. During the period of 1960-1965, life expectancy at birth was 53.6 years for males and 56.9 years for females. By the end of the following 20 years (1980-1985), life expectancy increased by 8.9 years for males and 14.1 years for females. It is projected that the life expectancy at birth will reach the same level of life expectancy in developed countries by the year 2000 .

\section{Rapidity of population aging}

Dramatic demographic transitions within a short period of time has accelerated population aging in Korea. Korea, which has already experienced large declines in fertility and mortality, has a tremendous momentum for further population aging. With respect to this phenomenon, Grigsby (1991) argues that even if fertility and mortality remain at 1985 levels, the elderly population will grow substantially. The projected declines in fertility and mortality will thus add to the momentum for even further population aging in Korea.

According to Choe \& Lee (1991), the speed of population aging in Korea is apparently greater than that of developed countries. The year when the proportion of those aged 65 and over reached $7 \%$ of the total population was 1930 in the UK, 1865 in France, 1970 in Japan, and 1945 in the USA. The time required to double this proportion was 45 years for the UK and 115 years for France. It is projected to take 26 years for Japan and 75 years for the USA. The proportion of those aged 65 and over in Korea is expected to reach to $7 \%$ by the year 2000 and it is estimated to take only 25 years to double the proportion of those aged 65 and over. Compared to the selected developed countries except Japan, the tempo of the increase in the proportions of those aged 65 and over from 7 to $14 \%$ is very accelerated.

\section{Changes in sex ratios and marital status of elderly}

Trends in the sex ratios (defined as the number of men per 100 women) of the aging population during the past few decades as well as projected trends through the year 2020 indicate that the sex ratio has constantly been less than 100 and is much lower among the old (Kim 1995). The sex ratio decreased until 1990 and is currently expected to increase. One plausible explanation for this pattern is an echo effect of the Korean War (1950-1953). Those cohorts aged 60 and over during the period of 1975-1990 were born before 1930. A 
Table 6. Proportions of currently married among the elderly, 1966-1990

\begin{tabular}{ccccccc}
\hline Age & 1966 & 1970 & 1975 & 1980 & 1985 & 1990 \\
\hline $\begin{array}{c}\text { Both sexes } \\
60+\end{array}$ & 48.0 & 50.3 & 52.0 & 53.0 & 55.9 & 54.9 \\
$65+$ & 41.3 & 41.6 & 44.6 & 45.0 & 47.0 & 47.2 \\
$70+$ & 32.0 & 33.5 & 35.3 & 36.1 & 39.2 & 38.6 \\
Male & & & & & & \\
$60+$ & 77.5 & 80.3 & 83.3 & 84.7 & 86.5 & 86.3 \\
$65+$ & 71.0 & 73.5 & 77.6 & 79.9 & 82.2 & 82.6 \\
$70+$ & 62.4 & 65.7 & 69.5 & 73.0 & 76.1 & 77.1 \\
Female & & & & & & \\
$60+$ & 28.7 & 29.4 & 31.0 & 31.6 & 35.2 & 34.5 \\
$65+$ & 22.0 & 21.7 & 24.3 & 24.3 & 27.4 & 26.0 \\
$70+$ & 15.4 & 15.5 & 17.3 & 17.3 & 20.4 & 18.3 \\
\hline
\end{tabular}

Source: Planning Bureau, Population and Housing Census Report $(1966,1970,1975,1980,1985,1990)$.

substantial proportion of males who were born before 1930 were at risk of being killed in battle during the Korean War.

The disproportionate number of deaths which occurred among these males might have left a high proportion of females widowed, leading to a significantly lower sex ratio among those aged 60 and over during the period of 1966-1990. Thus, the proportion of currently married elderly is much lower for females than for males (see Table 6). Table 6 also indicates that as with the younger cohorts, the proportion of currently married elderly has consistently increased over time.

\section{Urbanization of the elderly}

Table 7 contains the urbanization rates of the elderly and the proportion of the elderly population in urban and rural areas during the past three decades. The Korean population has experienced rapid urbanization, but the urbanization rate for the older population has been lower than that for the total population. Among the total population, the proportion of urban residence was $28 \%$ in 1960. This proportion continued to increase during the following three decades, reaching $74.4 \%$ in 1990 . For those aged 60 and over, however, the proportion of urban residence increased from $19.1 \%$ in 1960 to $54.7 \%$ in 1990.

While the urbanization rate for the older population indicated a continuous rise, the proportion of the older population in both urban and rural areas decreased until the mid-1960s and then increased. This pattern reflects the 
Table 7. Urbanization rates of the elderly and the proportions of the elderly in regional population in Korea, 1960-1990

\begin{tabular}{lccccccc}
\hline Specific urbanization & 1960 & 1966 & 1970 & 1975 & 1980 & 1985 & 1990 \\
\hline Age & & & & & & & \\
Total age population & 28.0 & 33.5 & 41.1 & 48.4 & 57.2 & 65.4 & 74.4 \\
Elderly population & & & & & & & \\
$\quad$ Age 60+ & 19.1 & 23.3 & 27.2 & 33.1 & 39.1 & 46.5 & 54.7 \\
Age 65+ & 18.6 & 22.4 & 25.6 & 31.7 & 38.0 & 45.3 & 53.6 \\
Age 70+ & 18.1 & 21.7 & 24.3 & 30.0 & 36.4 & 44.3 & 52.5 \\
\% of elderly in urban population & & & & & & \\
Age 60+ & 4.1 & 3.6 & 3.6 & 3.8 & 4.1 & 4.9 & 5.6 \\
Age 65+ & 2.5 & 2.2 & 2.1 & 2.3 & 2.6 & 3.0 & 3.6 \\
Age 70+ & 1.4 & 1.2 & 1.1 & 1.2 & 1.4 & 1.7 & 2.1 \\
\% of elderly in rural population & & & & & & \\
Age 60+ & 6.8 & 6.1 & 6.7 & 7.3 & 8.6 & 10.5 & 13.5 \\
Age 65+ & 4.2 & 3.9 & 4.2 & 4.6 & 5.6 & 6.8 & 9.0 \\
Age 70+ & 2.4 & 2.1 & 2.5 & 2.6 & 3.3 & 4.1 & 5.4 \\
\hline
\end{tabular}

Urbanization rate $=$ urban population/total population $\times 100$; percentage of the elderly $=$ age $60+(65+$ or $70+) /$ regional total population $\times 100$.

Sources: Economic Planning Bureau, Population and Housing Census Report (1966, $1970,1975,1980,1985,1990)$.

trend of population aging in Korea. As already indicated in Table 7, the proportion of elderly decreased from 1960 to 1966 and then continued to increase. A closer examination of the differences in the proportion of the older population in rural and urban areas reveals that, throughout the past three decades, the proportion of older people in rural area constantly outnumbered the corresponding proportion in urban population.

Furthermore, the increase in the proportion of older people has been higher in rural areas than in urban areas. In 1960, those aged 60 and over encompassed $4.1 \%$ of urban population and $6.8 \%$ of rural population. These numbers grew to $5.6 \%$ in urban areas and $13.5 \%$ in rural areas after 30 years. This discrepancy is mainly due to the massive outmigration from rural to urban areas and the outmigration has been mainly among younger people (Moon 1978; Kim 1987).

\section{Living arrangements}

Changes in the living arrangements of the older population is presented in Table 8. Two major features of the changes during this period are the increased proportion of those living alone and the subsequent decreased proportion of those living with family members. The proportion of the elderly living alone 
Table 8. Changes in the living arrangements of the elderly in Korea between 1981 and 1988

\begin{tabular}{lrrc}
\hline Living arrangements & $\begin{array}{l}1981 \\
(\%)\end{array}$ & $\begin{array}{l}1988 \\
(\%)\end{array}$ & $\begin{array}{l}\text { Changes in } \\
\text { the rates }\end{array}$ \\
\hline Living alone & 4.3 & 7.7 & 3.4 \\
Living with spouse & 52.7 & 53.4 & 0.7 \\
Living with married sons & 54.7 & 41.8 & -12.9 \\
Living with married daughters & 4.5 & 4.3 & -0.2 \\
Living with sons-in-law or daughters-in-law & 52.7 & 37.5 & -15.2 \\
Living with unmarried children & 31.5 & 26.6 & -4.9 \\
Living with grandchildren & 58.0 & 47.0 & -11.0 \\
Living with relatives & 2.3 & 1.8 & -0.5 \\
Living with others & 0.8 & 0.5 & -0.3 \\
\hline
\end{tabular}

Adapted from Kim \& Choe (1992: 94).

Sources: Korean Gallup, Life style and value system of the aged in Korea, based on surveys in 1981 and 1988 (1990).

was $4 \%$ in 1981 , but it increased to $8 \%$ in 1988 . The proportion of the elderly living with their spouse shows only a slight increase. However, the patterns of living with married sons, sons-in-law or daughters-in-law and grandchildren changed significantly between 1981 and 1988: the proportion of the elderly living with married sons decreased from $55 \%$ in 1981 to $42 \%$ in 1988; the proportion of the elderly living with sons-in-law or daughters-inlaw decreased from 53 to $37.5 \%$; and the proportion of the elderly living with grandchildren from 58 to $47 \%$. Living arrangements of the elderly is closely related to the financial situation of the elderly. According to a survey on the support of the elderly in Korea (Rhee, Kwon \& Lee 1990), the proportion of the elderly who receives financial support among those living with family members is $64 \%$ whereas the proportion among those living alone is only $31 \%$.

\section{Social and economic implications}

Population aging in Korean society has emerged as a new concern. Accordingly, some potential policy implications are suggested. These include: (1) an upsurge in respect for the aged and an increased filial piety spirit, (2) establishing income maintenance of the elderly through social programs, and (3) developing a heath care system for the elderly (Choe \& Lee 1991: Choi 1992). In the following, we will briefly examine the necessity of increased filial piety, the economic security of the Korean elderly and their long-term health care options. In addition, policy concerns related to these issues will be identified. 


\section{Respect/filial piety}

Despite the forces of industrialization and urbanization, the family in Korea is still important in supporting the elderly. Family support for the elderly is closely related to the filial piety (Sung 1990). Filial piety is a value based on the respect for the aged, which is an important factor affecting family support and living arrangements of the elderly.

Living arrangements of the elderly is critical in the support for the elderly. Living together with the elderly is considered as the best way of providing support for the elderly because living together makes possible every kind of support. However, changing family types and increased individualism due to the forces of industrialization and urbanization may weaken the strong ties in the family, thus reducing the family support for the elderly. The proportion and the absolute number of the elderly in Korea have rapidly increased and will increase more drastically in the future.

As a consequence of the rapid changes both in socioeconomic development and population aging, the role of the government should be extended in providing welfare for the elderly. However, the role of the government would be limited to some extent because it is impossible for the government to take full responsibility if the number of the elderly unlimitedly increase. In this situation, the family should continuously take part in the care of the elderly. Without increased filial piety, supporting the elderly in the family would be very difficult. Thus, an upsurge in respect for the aged and increased filial piety should be emphasized.

\section{Economic security}

Economic security is crucial for older people. However, the 1984 Korea Elderly Survey revealed that about half of the elderly people aged 60 and over had financial difficulties. According to the 1988 Korea Gallup Survey, the proportion of those who reported financial difficulties had increased to almost two-thirds of the elderly respondents. Further, the 1988 Survey indicates that about three-quarters of those aged 60 and over reported receiving financial support from their adult children. Personal resources such as property and savings as well as societal provisions including pensions and public assistance were quite limited (Hur 1993).

Most Korean elderly take it for granted that they will receive financial help from their own children. Contrary to this expectation, however, there are many circumstances under which such support is not available from their children. An increasing number of Korean elderly suffer from financial difficulties because of their children's avoidance of, or inability to provide financial 
support (Choi 1992). This problem is reflected in the rising demand for social welfare for the elderly.

A major factor causing a sharp decline in the income of Korean elderly and their ensuing dependence on their children is the mandatory retirement system. The retirement system in Korea has been in practice since the early 1960s. Average retirement age for most employees is still below age 60, although the specific retirement age differs by the industry. Because the national pension program covering most workers provides benefits for those insured 20 years and more and aged 60 and over, retirees before age of 60 have to wait several years to become eligible for the national pension (Kim 1993). Furthermore, because the national pension program only started in 1988 , the majority of the current elderly population are not eligible for the benefits.

The major source of income for those subject to the mandatory retirement system is the retirement benefits given under the provision of the Labor Standards Act. However, these benefits are not sufficient to maintain a minimum living standard (Min 1985). Other factors contributing to the economic insecurity of elderly people are the lack of social security provisions, excessive support for their children, difficulties in reemployment after retirement, and unstable employment and low wages.

The rapid decline in the proportion of children and increases in the proportion of older people since the mid 1960s brought about changes in the dependency ratios. If we define older people as those aged 60 and over, the total age dependency ratio fell significantly from 94.9 in 1966 to 50.2 in 1990 . According to projections, by the year 2020 , the total age dependency ratio will fall to the 40s during 1995-2010, which is the 'golden period'. This ratio will then climb up to 47.9 in 2015 and 55.3 in 2020 (see Table 9). The 'golden period' is due to the large number of people born in around the 1960s entering the labor force while the size of cohorts born during and after the 1980s is much smaller. Grigsby (1991) suggests that Korea needs to take advantage of this period when the traditional labor force is large to continue economic growth.

With respect to the specific components of total age dependency ratios, the ratio of those aged 15 and under to those aged 15-59 continues to decrease throughout 1966-2020. The ratio of those aged 60 and over to those aged 15-59 decreased during 1966-1975, and then will rise continuously until the year 2020. By 2020, the ratio of those aged 60 and over to those aged 15-59 is expected to outnumber the ratio of those aged 15 and under to those aged 15-59. Based on the current retirement age of 60 , the ratio of retirees to workers was 11.6 to 100 in 1990 . This ratio can be maintained by raising the 
Table 9. Dependency ratio in Korea, 1966-2020

\begin{tabular}{lcccccc}
\hline Dependency ratio & 1966 & 1970 & 1975 & 1980 & 1985 & 1990 \\
\hline Child/working age & 84.8 & 80.2 & 67.7 & 56.2 & 47.5 & 38.6 \\
Elderly/working age & 10.1 & 10.3 & 10.0 & 10.2 & 10.9 & 11.6 \\
Total dependency & 94.9 & 90.5 & 77.6 & 66.4 & 58.5 & 50.2 \\
\hline & & & & & & \\
Dependency ratio & 1995 & 2000 & 2005 & 2010 & 2015 & 2020 \\
\hline Child/working age & 35.2 & 31.1 & 30.1 & 28.4 & 25.7 & 25.0 \\
Elderly/working age & 13.4 & 15.7 & 19.1 & 20.4 & 22.2 & 30.3 \\
Total dependency & 48.6 & 46.8 & 48.2 & 48.8 & 47.9 & 55.3 \\
\hline
\end{tabular}

Sources: Economic Planning Board, Population and Housing Census Report (1966, 1970, 1975, 1980, 1985, 1990); Statistics Bureau, Future Projected Population, 1990-2021 (1990).

age of retirement to 64 in 2005 . If the age of retirement is raised to 69 in 2020 , the ratio of retirees to workers will be 10.2 to 100 .

Nevertheless, there would be objections to the suggestion of raising the retirement age. The major concern would be the unfavorable impact on upward mobility for the younger population. Keyfitz (1972) illustrated the way that an increase in the number of older persons slows down upward mobility on the part of younger people by analyzing the extent that the age of promotion depends on the rate of population increase under different mortality schedules and other circumstances. The aged would be perceived as holding on to the good jobs. This may generate intergenerational conflict. Given that the elderly must be provided for, and if the older age dependency ratio is high, a choice must be made between allowing the elderly to keep their jobs and supporting them with tax money (Liang, Yu \& Chen 1986).

\section{Long-term care}

Population aging generates a substantial demand for long-term care. In Korea, the majority of such care has been provided by the family, with institutionalized care reserved as the last resort. In 1991, only 6,735 elderly persons ( $0.3 \%$ of those aged 65 and over) were institutionalized. This is due to several factors. First, the traditional value of filial piety emphasizes that the provision of personal care for one's parents by their children. This strongly discourages the family from accepting care services from non-family members. Second, formal institutional care and community based programs are not well developed due to the lack of involvement of the government. Third, the relatively 
small age composition of the elderly population accounts for the low rate of institutionalization.

However, it is expected that many Korean elderly will have increasing difficulties in obtaining care services at home. This may be due to the following factors: an increase in the number of disabled elderly, changing values regarding family support, the reduced family size (fertility), and increasing participation in the workforce and social activities of women who served as primary providers of care for the elderly.

Health care costs for the elderly are much higher than for any other population. Medical care costs per elderly person aged 65 and over are approximately 1.7 times those of the entire population (Rhee, Chang, Roh \& Park 1993). In 1989 , national medical insurance was put into effect for the whole population so that everyone is supposed to be covered by some kind of public medical care insurance policies. However, many of the elderly cannot afford to pay for the medical insurance out of their own pockets. Taking this fact into consideration, the government should provide special medical programs for the poor elderly.

\section{Summary and Conclusion}

A cross-sectional analysis of the Korean elderly using the 1988 National Health Survey indicates low educational attainment levels of the older population and an overwhelming predominance of widowhood for older women. With respect to economic activity, there is a substantial proportion of the elderly who are economically active, with a high concentration in the farming and fishing industries. Self-report of chronic diseases shows that about one of three Korean elderly have some type of chronic disease.

Analysis of changes in the characteristics of the Korean elderly over the past three decades reveals the following phenomena: an increase in the absolute size and proportion of the older population; an increase in the proportion of older people reflected in the dependency ratio; an increasingly imbalanced sex ratio; and substantial sex differences in the proportions of currently married elderly. In addition, the analysis revealed that the urbanization rate for the elderly lagged behind the urbanization rate for the total population and a greater increase in the proportion of elderly residing in rural areas than in the cities is due primarily to the heavy outmigration of young people from rural areas.

In relation to the support of the elderly in conjunction with further development, Mason (1992) raises a question: Is there evidence to suggest, with further development, the elderly in Asia are likely to receive less care or support from their children? In a reply to this question, she mentions that the 
answer given by most experts on aging in Asia is a qualified 'yes'. She argues that norms about the care of the elderly by their children were traditionally strong in most Asia and appear to remain strong, but despite this, traditional patterns of coresidence are eroding in many countries. The further economic growth and urbanization are likely to erode the family's ability to care for the elderly.

Between 1981 and 1988 the proportion of the Korean elderly living alone increased while the proportion of those living with family members decreased. The elderly living alone suffer from serious economic problems. Thus, although the proportion of the Korean elderly receiving support is still relatively high, an increasing proportion of the elderly living alone might indicate that the tradition of strong family support is somewhat weakening owing to the rapid socioeconomic transformation in recent decades. According to the projections, by 2025 , the elderly population will continue to grow and the proportion of older people in the dependency ratio will become greater than that of children.

The aging issues and policies related to these issues in the future will be quite different from today, because changes in social environment will coincide with the process of population aging. Population characteristics of the elderly in the coming century will thus be significantly different from those at present. For instance, the educational composition of the elderly population is projected to change substantially between 1980 and 2020 (Hermalin \& Christenson 1991). The literacy rate among males aged 60 and over will increase from less than $50 \%$ to near complete literacy over the forty year projection period.

The improvement in the literacy rate for older women is projected to be even greater than for males during the same period. The literacy rate for older women was $20 \%$ in 1980 but it will increase to over $95 \%$ by 2020 . The proportion of males aged 60 and over who have at least a secondary education will increase steadily from less than one quarter in the 1980s to three quarters by the year 2020 . These changes will significantly affect the role of the elderly both in the family and the society and will also influence the pattern of the support for the elderly.

As a consequence of the drastic socioeconomic changes and the increase both in the absolute size and the proportion of the elderly population, a measure of responsibility for the welfare of the elderly may shift from the family to the government. Although the Korean government recently established various types of services for the elderly, the scope of these services is very limited (Kim \& Choe 1992). The 1984 Elderly Survey in Korea shows that the proportion of the elderly receiving public assistance is less than $2 \%$ of the total older population, and those receiving medical insurance and pension 
benefits account for only 3 and $2 \%$, respectively. This implies the need for a broader array of services and better access to them by a larger segment of the elderly population than is currently the case.

\section{Acknowledgments}

This research was supported by a grant provided by the Office of Vice President for Research and Institute of Gerontology at University of Michigan and was primarily based on the data set provided by the Korean Institute for Health and Social Affairs, Seoul, Korea.

\section{References}

Choe, E.H. (1989). Population aging in the Republic of Korea. Bangkok: ESCAP, Asian Population Studies Series, No. 97.

Choe, E.H. \& Lee, J.S. (1991). Social policies for the elderly: Current status and prospects. In: Population aging in Asia (pp. 62-65). Bangkok: ESCAP, Asian Population Studies Series, No. 108.

Choi, S.J. (1992). Ageing and social welfare in South Korea. In: D.R. Phillips (ed.), Ageing in East and South-East Asia (pp. 148-166). London: Edward Arnold.

Coale, A. (1964). How a population ages or grows younger. In: R. Freedman (ed.), Population: The vital revolution (pp. 47-58). New York: Garden City.

Grigsby, J.S. (1991). Paths for future population aging, The Gerontological Society of America 31: 195-203.

Hermalin, A.I. \& Christenson, B.A. (1991). Comparative analysis of the changing educational composition of the elderly population in five Asian countries: A preliminary report. Ann Arbor: Population Studies Center, PSC Research Report No. 91-11.

Hur, J. (1993). The elderly and health: Physical health. In: Asian Foundation (ed.), Modern society and welfare services for the aged. Seoul.

Kim, I.K. (1987). Socioeconomic development and fertility in Korea. Seoul National University, Population and Development Studies Center.

Kim, I.K. (1995). Population aging and policy implications in Korea. Paper presented at an International Conference on Korea in Global Society, Seoul, Korea.

Kim, I.K. \& Choe, E. (1992). Support exchange patterns of the elderly in Korea, Asia-Pacific Population Journal 7: 89-104.

Kim, I.Y. (1993). A comparative study of living arrangements among elderly Asian immigrants in the United States. Unpublished Doctoral Dissertation. Brown University.

Kim, T.L., Ross, J.A. \& Worth, Q.C. (1972). The Korean National Family Planning Program. New York: The Population Council.

Kwon, T.H., Lee, H.Y., Chang, Y. \& Yu, E. (1975). The population of Korea. Seoul: Seoul National University Press.

Lee, H.Y. (1980). Demographic transition in Korea, Bulletin of the Population and Development Studies Center 8: 5-17.

Liang, J., Yu, E.J. \& Chen, X. (1986). Population aging in the People's Republic of China, Social Science and Medicine 23: 1353-1362.

Liang, J., Gu, S. \& Krause, N. (1992). Social support among the aged in Wuhan, China, Asia-Pacific Population Journal 7: 33-62.

Martin, L. (1988). The aging of Asia, Journal of Gerontology: Social Sciences 43: 99-113. 
Mason, O.K. (1992). Family change and support of the elderly in Asia: What do we know?, Asia-Pacific Population Journal 7: 13-32.

Min, J.S. (1985). Retirement benefits and pension system, Korean Social Security Studies 1: $61-69$.

Moon, S.G. (1978). Urban-rural disparity in socioeconomic and demographic changes in Korea, 1960-1970. Bulletin of the Population and Development Studies Center, Seoul National University.

Myers, G. (1983). Mortality declines, life extension and population aging. Proceedings of selected papers of International Union for Scientific Study of Population, Manila.

Rhee, K.O., Kwon, J. \& Lee, W. (1990). A study on the support for the elderly. Seoul: Korean Institute for Health and Social Affairs.

Rhee, K.O., Kwon, J. \& Kang, H. (1991). A study on the establishment of home help system in Korea. Seoul: Korean Institute for Health and Social Affairs.

Rhee, K.O., Chang, M., Roh, Y. \& Park, J. (1993). Development of welfare policies for the elderly. Seoul: Korean Institute for Health and Social Affairs.

Sung, K.T. (1990). A new look at filial piety: Ideals and practices of family-centered parent care in Korea, Gerontologist 30: 610-617.

Tu, E.J., Liang, J. \& Li, S. (1989). Mortality decline and Chinese family structure: Implications for old age support, Journal of Gerontology: Social Sciences 44 (suppl.): s157-s168.

Address for correspondence: Ik Ki Kim, PhD, Department of Sociology, Dongguk University, Seoul, Korea

Phone: +82 2 260-3260; Fax: +82 2 277-1274; E-mail: ikki@ cakra.dongguk.ac.kr 